\title{
Novel approaches for the treatment of unresectable malignant pleural mesothelioma: A focus on immunotherapy and target therapy (Review)
}

\author{
ERIKA RIJAVEC $^{1}$, FEDERICA BIELLO ${ }^{2}$, GIULIA BARLETTA ${ }^{3}$, CHIARA DELLEPIANE ${ }^{3}$ and CARLO GENOVA ${ }^{4,5}$ \\ ${ }^{1}$ Medical Oncology Unit, Fondazione IRCCS Ca' Granda Ospedale Maggiore Policlinico, I-20122 Milan; \\ ${ }^{2}$ Department of Translational Medicine, Division of Oncology, University of Eastern Piemonte, I-28100 Novara; \\ ${ }^{3}$ Medical Oncology Unit, ${ }^{4}$ Academic Oncology Unit, IRCCS Ospedale Policlinico San Martino; \\ ${ }^{5}$ Department of Internal Medicine and Medical Specialties, Università degli Studi di Genova, I-16132 Genoa, Italy
}

Received October 18, 2021; Accepted January 13, 2022

DOI: $10.3892 / \mathrm{mco} .2022 .2522$

\begin{abstract}
Malignant pleural mesothelioma (MPM) is considered a relatively uncommon disease but its incidence is increasing worldwide. Patients affected by MPM have a very severe prognosis and have been often occupationally and environmentally exposed to asbestos. In recent years, checkpoint inhibitors have dramatically revolutionized the paradigm for the treatment of several malignancies. Several efforts have also been made to improve the survival outcomes of patients with MPM and after decades, the standard-of-care systemic treatment for unresectable MPM, based on first-line combination chemotherapy with cisplatin and pemetrexed, has changed. In addition to checkpoint inhibitors, other types of treatments, such as molecularly targeted therapy have been evaluated. However, to date, the results of these investigations are not very encouraging. The aim of the present review is to provide a comprehensive overview of the most relevant data of clinical trials regarding recent treatment strategies of MPM with a particular focus on immunotherapeutic and targeted approaches.
\end{abstract}

\section{Contents}

1. Introduction

2. Malignant pleural mesothelioma (MPM)

3. Immunotherapy

4. Targeted agents in MPM

5. Conclusion

Correspondence to: Dr Erika Rijavec, Medical Oncology Unit, Fondazione IRCCS Ca' Granda Ospedale Maggiore Policlinico, via Francesco Sforza 28, I-20122 Milan, Italy

E-mail: ery80x@yahoo.it

Key words: malignant pleural mesothelioma, immunotherapy, ipilimumab, nivolumab, durvalumab, pembrolizumab, tremelimumab, target therapy

\section{Introduction}

Malignant pleural mesothelioma (MPM) is an aggressive disease of the pleura, associated with exposure to asbestos and globally poor outcomes and divided among epithelioid, sarcomatoid, and mixed histology, accounting for 69, 19 and 12\%, respectively. While MPM has generally been described as a rare malignancy, the burden of this disease account for more than 30,000 annual deaths in the United States. Notably, MPM develops after 3-4 decades after initial exposure to asbestos. While some MPM patients can be treated with radical approaches, the benefit of surgery, even when technically feasible, is still object of debate. Currently, selected patients affected by non-sarcomatoid MPM and with good performance status might receive systemic antineoplastic treatment as part of multi-modal approaches including neoadjuvant chemotherapy, surgery (pleuro-pneumonectomy or radical pleural decortication), and radiation therapy. However, most patients only receive systemic antineoplastic treatment as the only antineoplastic treatment, either due to disease extension and histology. For years, the mainstay of systemic treatment in first line for MPM has been represented by chemotherapy regimens including a platinum-derivate (either cisplatin or carboplatin) and an antimetabolite (pemetrexed), while second-line treatments are far less standardized and usually involve single-agent treatments such as gemcitabine and vinorelbine (1).

More recently, novel antineoplastic agents have been employed in MPM, including both immune checkpoint inhibitors (ICIs) and targeted agents.

The aim of this review is to report the most recent updates regarding the use of novel antineoplastic agents in MPM, with specific reference to immune checkpoint inhibitors and targeted agents. To this aim, we have searched through the currently available literature published on PubMed, PMC and NLM databases to identify suitable studies involving novel agents for the treatment of pleural mesothelioma, with specific reference to immune checkpoint inhibitors and targeted agents; furthermore, we evaluated abstracts from the most relevant oncology conferences held by international associations, including the European Society for Medical 
Oncology (ESMO), American Society for Clinical Oncology (ASCO), and International Association for the Study of Lung Cancer (IASLC).

Based on our findings, we organized the manuscript with the following outline: ICIs (described according to line of treatment and involved drugs); targeted agents (described according to the involved molecular target). The drugs discussed in this review are summarized in Table I.

\section{Malignant pleural mesothelioma (MPM)}

At diagnosis, approximately $60-90 \%$ of patients affected by MPM presented pleural thickening and pleural effusion, accounting for the most common presenting symptoms of dyspnea and chest wall pain. Other frequent complaints included fever, fatigue, weight loss, and sweats (2).

The pathologic diagnosis of MPM should always be based on the results obtained from an adequate biopsy.

Epithelioid mesothelioma, often associated with the most favorable prognosis, is composed of polygonal, cuboidal, or oval cells that frequently mimic reactive mesothelial cells. Sarcomatoid mesothelioma, which is the more aggressive histologic subtype, usually consists of spindle cells but can be composed of lymphohistiocytoid cells and/or contain heterologous rhabdomyosarcomatous, osteosarcomatous, or chondrosarcomatous elements. Biphasic mesothelioma instead contains both epithelioid and sarcomatoid areas within the same tumor (3).

\section{Immunotherapy}

The use of immunotherapy for the treatment of unresectable MPM has been explored in multiple trials, including ICIs either as single-agent or as part of combination regimens. The following paragraphs report the most relevant findings according to employed agents and lines of treatment. Notable outcomes have been summarized in Table II.

\section{First-line}

Ipilimumab plus nivolumab. In the randomized, phase III CheckMate 743 study, 605 MPM patients were randomized (1:1) to receive first-line treatment with nivolumab $(3 \mathrm{mg} / \mathrm{kg}$ every 2 weeks) and ipilimumab (1 mg/kg every 6 weeks) for up to 2 years or chemotherapy regimen with platinum and pemetrexed for a maximum of 6 cycles. The primary endpoint of the study was overall survival (OS). A significant OS benefit has been reported in patients treated with combination immunotherapy compared to chemotherapy: median OS was 18.1 months with nivolumab plus ipilimumab compared to 14.1 months with chemotherapy (HR, 0.74; $\mathrm{P}=0.002$ ).

The 2 -year OS rate was $41 \%$ with immunotherapy and $27 \%$ with chemotherapy. No significant differences in terms of progression-free survival (PFS) were observed between the two arms: 6.8 months with nivolumab plus ipilimumab and 7.2 months with chemotherapy. Although objective response rates (ORR) were similar (40 vs. 43\%), the median duration of response was significantly longer with combination immunotherapy (11.0 versus 6.7 months).

In the experimental arm, median OS was similar between patients with tumor PD-L1 expression $<1 \%$ and $\geq 1 \%$ (17.3 vs.
18 months); conversely, in the chemotherapy arm, median OS was significantly longer among patients with PD-L1 $<1 \%$ than among patients with PD-L1 $\geq 1 \%$ ( 16.5 vs. 13.3 months). Results of a pre-planned subset analysis considering histologic subtypes showed a more prolonged median OS with immunotherapy compared to chemotherapy in patients with non-epithelioid histology (18.1 vs. 8.8 months; HR, 0.46). Conversely, in epithelioid histology, OS benefit with immunotherapy did not reach statistical significance (18.7 vs. 16.5 months; HR, 0.86). The percentage of treatment-related toxicity (TRAEs) was similar between the two arms of treatment: $30 \%$ with nivolumab plus ipilimumab and $32 \%$ with chemotherapy.

The most frequently TRAEs reported with the combination of immunotherapy were dermatological, gastrointestinal, endocrine, hepatic, pulmonary, renal, and hypersensitivity/ infusion reaction events (4).

Patients treated with ipilimumab plus nivolumab compared to those who received chemotherapy maintained quality of life and experienced a decreased risk of definitive deterioration in disease-related symptoms as well as health-related quality of life (HRQoL) (5).

In October 2020, based on findings of CheckMate 743, the Food and Drug Administration (FDA) approved the combination of nivolumab (360 mg every 3 weeks) plus ipilimumab $(1 \mathrm{mg} / \mathrm{kg}$ every 6 weeks), until disease progression, intolerable toxicities or up to 2 years, in patients with unresectable previously untreated MPM (6).

At ESMO Congress 2021, Peters et al reported a 3-year update of efficacy results from CheckMate 743. The combination of nivolumab with ipilimumab continued to demonstrate a survival benefit compared with chemotherapy (3-years OS rate of 23 vs. $15 \%$, respectively). Furthermore, exploratory biomarker analyses showed that a high score of 4-gene inflammatory signature (CD8A, STAT1, LAG3, and CD274) seems to correlate with improved survival benefit with immunotherapy (7).

Durvalumab plus chemotherapy. First-line treatment with durvalumab plus chemotherapy has been investigated in unresectable MPM patients in two phase II trials: PrE505 and DREAM study with encouraging results $(8,9)$.

In the PrE505 study, 55 patients enrolled in 15 hospitals in the United States (US), received platinum/pemetrexed-based chemotherapy with durvalumab for a maximum of 6 cycles followed by durvalumab maintenance up to 1 year. The primary endpoint was OS. The combination of chemotherapy plus durvalumab showed a remarkable OS of 21.1 months and the OS rate was $70 \%$ at 1 year (6).

In the DREAM study, 55 patients from 9 hospitals in Australia were treated with platinum/pemetrexed-based chemotherapy in combination with durvalumab (at the fixed dose of $1,125 \mathrm{mg}$ ) for a maximum of 6 cycles followed by durvalumab maintenance up to 1 year. The primary endpoint was PFS at 6 months, according to the immune-related modified Response Evaluation Criteria in Solid Tumors (ir-RECIST). At 6 months, 34 patients (57\%) were progression-free. The combination treatment showed an acceptable safety profile (7).

Results of the ongoing phase III DREAM3R evaluating the effectiveness of adding durvalumab to platinum/pemetrexedbased chemotherapy in advanced MPM are awaited (10). 
Table I. Overview of the drugs discussed in the review.

\begin{tabular}{lll}
\hline Treatment & Line of treatment & Agents \\
\hline Checkpoint inhibitors & First & Ipilimumab + nivolumab \\
& Durvalumab + chemotherapy \\
& Nivolumab \\
& & Ipilimumab + nivolumab \\
& & Pembrolizumab \\
& & Tremelimumab \\
Targeted therapy & & Durvalumab + tremelimumab \\
Antiangiogenic drugs & First & Bevacizumab \\
& & Nintedanib \\
Anti-mesothelin drugs & & Cediranib \\
& Second or later & Ramucirumab \\
& First & Amatuximab \\
Other approaches & Second or later & SS1P \\
\hline
\end{tabular}

\section{Second or later lines}

Nivolumab. NivoMes study was the first phase II trial investigating nivolumab in relapsed MPM patients. Thirty-eight patients previously treated with at least one prior chemotherapy regimen received nivolumab $(3 \mathrm{mg} / \mathrm{kg}$ every 2 weeks). The primary endpoint of the study was disease control rate (DCR) at 12 weeks. The trial showed encouraging results: after the 12 weeks of treatment, DCR was $50 \%$, and notably, five patients experienced a partial response. The anti-PD-1 showed an acceptable safety profile: $26(76 \%)$ patients reported TRAEs of any grade and the most common toxicities described were fatigue (29\%) and pruritus (15\%) (11).

Okada et al (12) evaluated the administration of nivolumab (240 mg every two weeks) until disease progression or unacceptable toxicity in 34 Japanese patients with unresectable MPM in the single-arm, phase II MERIT trial. All the patients had received one to two lines of previous therapies including platinum plus pemetrexed chemotherapy. The primary endpoint of the trial was ORR.

At a minimum follow-up of 16.8 months, ORR was $29 \%$. Notably, tumor shrinkage has been observed also in patients with histologic subtypes known for their poor response to treatments. According to histologic subtypes, indeed, ORR was $26 \%(7 / 27), 25 \%(1 / 4)$, and $67 \%(2 / 3)$ in patients with epithelioid, biphasic, and sarcomatoid histology, respectively. Median OS and PFS were 17.3 and 6.1 months, respectively. Prolonged OS and PFS were observed in patients with PD-L1 $\geq 1 \%$ compared to those with PD-L1 $<1 \%$, however, the differences were not statistically significant.

Severe AEs (grade 3 or 4 ) were described in $47 \%$ of patients enrolled and the most frequently toxicities reported were diarrhea, gamma-glutamyltransferase increased and pneumonitis.

After 3 years of follow-up, nivolumab demonstrated sustained OS and PFS rates (23.5 and $12.7 \%$, respectively) in pre-treated MPM patients (13). Based on these findings, nivolumab has been approved for the second-line treatment of MPM patients in Japan.

The administration of nivolumab has also been investigated in the randomized, double-blind, phase III CONFIRM trial enrolling 332 patients affected by unresectable pleural or peritoneal mesothelioma, who had received at least two prior lines of therapy, in the United Kingdome (UK). The enrolled patients were randomized $(2: 1)$ to receive nivolumab $(n=221)$ at the dose of $240 \mathrm{mg}$ every two weeks or placebo $(n=111)$ until disease progression, unacceptable toxicity or for up 2 years. The co-primary endpoints of the study were OS and PFS (14).

In January 2021, preliminary results of the study were presented during the IASLC 2020 World Conference on Lung Cancer Singapore Worldwide Virtual Event. The anti-PD-1 met all the study's primary efficacy endpoints. Patients treated with nivolumab showed a significantly longer OS (9.2 vs. 6.6 months; HR, 0.72) and PFS (3 vs. 1.8 months; HR, 0.61) compared to those who received placebo. A significant benefit on OS has been reported with nivolumab in patients with epithelioid histology compared with those with non-epithelioid histology (9.2 vs. 6.6 months; HR, 0.72). PD-L1 expression did not appear to predict survival benefit with checkpoint inhibitor. The incidence of grade 3 and 4 AEs did not differ across treatment arms: $45 \%$ with nivolumab compared to $42 \%$ with placebo (15).

Recently, more updated results of the study have been published. Median investigator-reported PFS was longer in patients treated with immunotherapy than placebo (3.0 vs. 1.8 months, HR, 0.67; $\mathrm{P}=0.0012$ ). Median OS was 10.2 months in the nivolumab arm compared with 6.9 months in the placebo arm (HR, 0.69; $\mathrm{P}=0.009)$. The one-year OS rates were $43.4 \%$ in the experimental arm and $30.1 \%$ in the placebo arm (16).

Ipilimumab plus nivolumab. The role of the combination of ipilimumab and nivolumab in previously treated MPM patients has been investigated in two phase II trials: MAPS2-IFCT1501 
Table II. Relevant outcomes of studies involving immune checkpoint inhibitors in MPM.

A, ICI-based combinations

\begin{tabular}{|c|c|c|c|c|c|}
\hline Regimen & $\begin{array}{l}\text { First author, } \\
\text { year (trial) }\end{array}$ & Trial design & Patients/setting & Main efficacy outcomes & Refs. \\
\hline \multirow[t]{3}{*}{$\begin{array}{l}\text { Ipilimumab plus } \\
\text { nivolumab }\end{array}$} & $\begin{array}{l}\text { Baas P, } 2021 \\
\text { (CheckMate 743) }\end{array}$ & $\begin{array}{l}\text { Randomized, } \\
\text { phase III trial } \\
(1: 1) \text {-ipilimumab } \\
\text { plus nivolumab vs. } \\
\text { platinum-based } \\
\text { chemotherapy }\end{array}$ & $\begin{array}{l}605 \text { patients; } \\
\text { first-line }\end{array}$ & $\begin{array}{l}\text { Advantage in terms of } \\
\text { median OS with ICIs } \\
\text { compared to chemotherapy } \\
(18.1 \text { vs. } 14.1 \text { months; } \\
\text { HR, } 0.74 ; \mathrm{P}=0.002)\end{array}$ & (4) \\
\hline & $\begin{array}{l}\text { Scherpereel A, } 2019 \\
\text { (MAPS2-IFCT1501) }\end{array}$ & $\begin{array}{l}\text { Randomized, } \\
\text { non-comparative, } \\
\text { phase II trial } \\
\text { (1:1)-nivolumab } \\
\text { vs. ipilimumab } \\
\text { plus nivolumab }\end{array}$ & $\begin{array}{l}125 \text { patients; } \\
\text { pre-treated }\end{array}$ & $\begin{array}{l}\text { 12-week DCR: } 50 \% \\
\text { (ipilimumab plus nivolumab); } \\
\text { 44\% (nivolumab) } \\
\text { Median OS: } 15.9 \text { months } \\
\text { (ipilimumab plus nivolumab); } \\
11.9 \text { months (nivolumab) } \\
\text { 2-year OS: } 31.7 \% \\
\text { (ipilimumab plus nivolumab); } \\
25.4 \% \text { (nivolumab) }\end{array}$ & $(17)$ \\
\hline & $\begin{array}{l}\text { Disselhorst MJ, } 2019 \\
\text { (INITIATE) }\end{array}$ & $\begin{array}{l}\text { Single-arm, } \\
\text { phase II trial }\end{array}$ & $\begin{array}{l}38 \text { patients; } \\
\text { pre-treated }\end{array}$ & 12-week DCR: $33 \%$ & (19) \\
\hline \multirow[t]{2}{*}{$\begin{array}{l}\text { Durvalumab plus } \\
\text { chemotherapy }\end{array}$} & $\begin{array}{l}\text { Forde PM, } 2020 \\
(\text { PrE505) }\end{array}$ & $\begin{array}{l}\text { Single-arm, } \\
\text { phase II trial }\end{array}$ & $\begin{array}{l}55 \text { patients; } \\
\text { first-line }\end{array}$ & Median OS: 21.0 months & (8) \\
\hline & $\begin{array}{l}\text { Nowak AK, } 2020 \\
\text { (DREAM) }\end{array}$ & $\begin{array}{l}\text { Single-arm, } \\
\text { phase II trial }\end{array}$ & $\begin{array}{l}55 \text { patients; } \\
\text { first-line }\end{array}$ & 6-month PFS: $57 \%$ & (9) \\
\hline \multirow[t]{2}{*}{$\begin{array}{l}\text { Durvalumab plus } \\
\text { tremelimumab }\end{array}$} & $\begin{array}{l}\text { Calabrò L, } 2018 \\
\text { (NIBIT-MESO-1) }\end{array}$ & $\begin{array}{l}\text { Single-arm, } \\
\text { phase II trial }\end{array}$ & $\begin{array}{l}40 \text { patients; } \\
\text { first-line or } \\
\text { pre-treated }\end{array}$ & $\begin{array}{l}\text { Immune-related ORR: } 28 \% \\
\text { Median immune-related PFS: } \\
8.0 \text { months; median OS: } \\
16.5 \text { months }\end{array}$ & $(25)$ \\
\hline & Venkatraman, 2019 & $\begin{array}{l}\text { Single-arm, } \\
\text { phase II trial }\end{array}$ & $\begin{array}{l}19 \text { patients; } \\
\text { pre-treated }\end{array}$ & $\begin{array}{l}\text { ORR: } 5 \% \\
\text { Median PFS: } 2.8 \text { months; } \\
\text { median OS: } 7.8 \text { months }\end{array}$ & $(27)$ \\
\hline
\end{tabular}

B, Single-agent ICI

\begin{tabular}{|c|c|c|c|c|c|}
\hline Regimen & $\begin{array}{l}\text { First author, } \\
\text { year (trial) }\end{array}$ & Trial design & Patients/setting & Main efficacy outcomes & Refs. \\
\hline \multirow[t]{3}{*}{ Nivolumab } & $\begin{array}{l}\text { Quispel-Janssen J, } \\
2018 \text { (NivoMes) }\end{array}$ & $\begin{array}{l}\text { Single-arm, } \\
\text { phase II trial }\end{array}$ & $\begin{array}{l}38 \text { patients; } \\
\text { pre-treated }\end{array}$ & 12-week DCR: 47\% & (11) \\
\hline & $\begin{array}{l}\text { Okada M, } 2019 \\
\text { (MERIT) }\end{array}$ & $\begin{array}{l}\text { Single-arm, } \\
\text { phase II trial }\end{array}$ & $\begin{array}{l}34 \text { patients; } \\
\text { pre-treated }\end{array}$ & $\begin{array}{l}\text { ORR: } 29 \% \\
\text { Median OS: } 17.3 \text { months } \\
\text { Median PFS: } 6.1 \text { months }\end{array}$ & (12) \\
\hline & $\begin{array}{l}\text { Fennel DA, } 2020 \\
\text { (CONFIRM) }\end{array}$ & $\begin{array}{l}\text { Randomized, } \\
\text { phase III trial } \\
(2: 1) \text {-nivolumab } \\
\text { vs. placebo } \\
\text { phase III trial } \\
\text { (2:1)-nivolumab } \\
\text { vs. placebo }\end{array}$ & $\begin{array}{l}332 \text { patients; } \\
\text { pre-treated }\end{array}$ & $\begin{array}{l}\text { Advantage in terms of median } \\
\text { OS with ICI compared } \\
\text { to placebo ( } 9.2 \text { months vs. } \\
6.6 \text { months; HR: } 0.72) \\
\text { Advantage in terms of } \\
\text { median PFS with ICI } \\
\text { compared to placebo } \\
\text { ( } 3 \text { months vs. } 1.8 \text { months; } \\
\text { HR: } 0.61) \\
1 \text {-year OS: } 43.4 \% \text { (ICI) vs. } \\
30.1 \% \text { (placebo) }\end{array}$ & $(15)$ \\
\hline
\end{tabular}


Table II. Continued.

B, Single-agent ICI

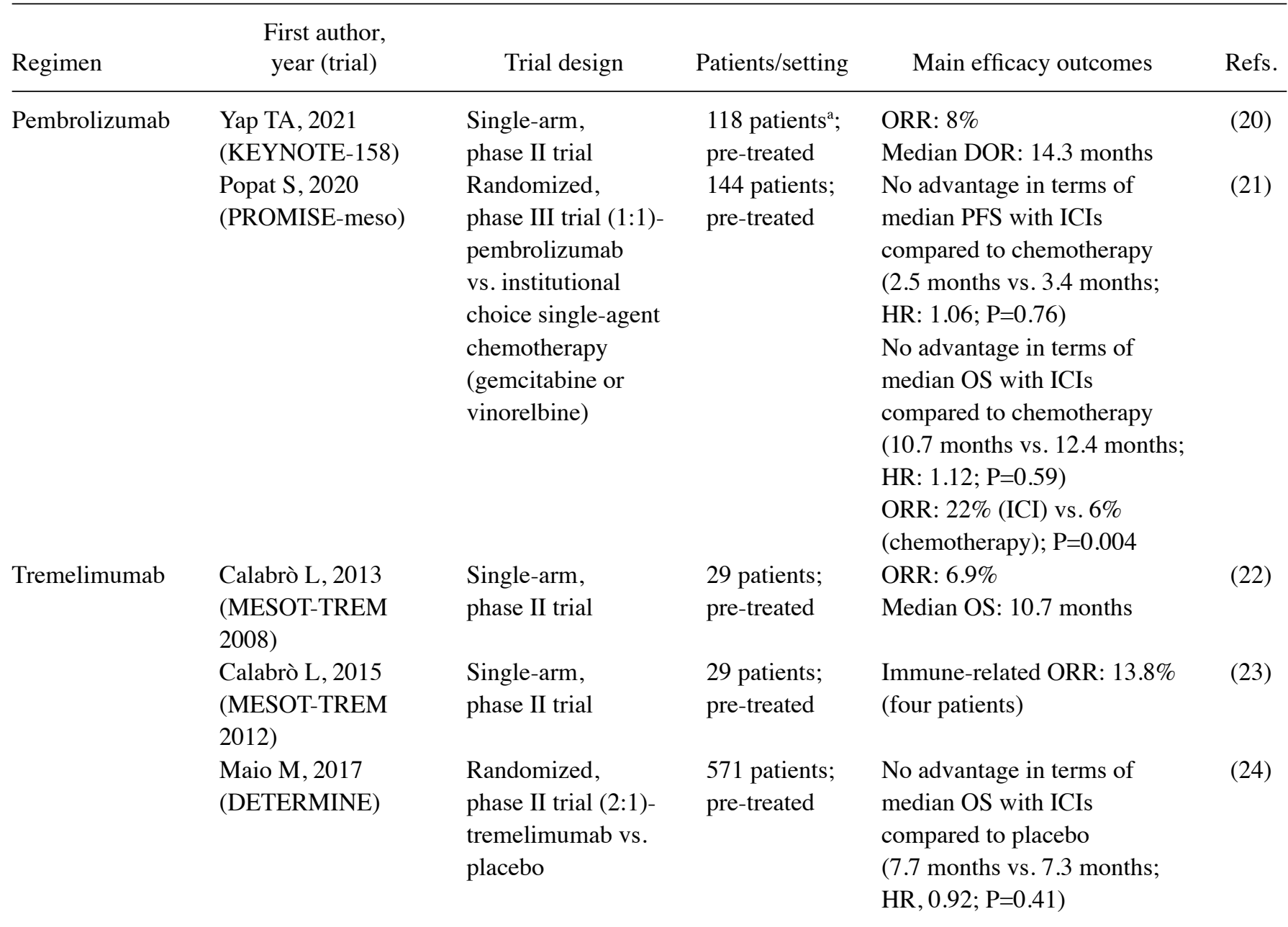

DCR, disease control rate; DOR, duration of response; HR, hazard ratio; ICI, immune checkpoint inhibitor; MPM, malignant pleural mesothelioma; ORR, objective response rate; OS, overall survival; PFS, progression-free survival. ${ }^{a}$ The study included patients with different malignancies; the reported data involve patients with MPM.

and INITIATE. In the multicentre MAPS2-IFCT1501 trial, 125 French patients were randomized $(1: 1)$ to receive in second or third-line nivolumab ( $3 \mathrm{mg} / \mathrm{kg}$ every 2 weeks) or ipilimumab ( $1 \mathrm{mg} / \mathrm{kg}$ every 6 weeks) plus nivolumab $(3 \mathrm{mg} / \mathrm{kg}$ every 2 weeks). In this study, not designed to compare the two different regimens, the primary endpoint was disease control rate (DCR) at 12 weeks. The trial met its primary endpoint (DCR achieved in at least $40 \%$ of patients). In the first 108 patients, indeed, DCR was $44 \%$ in the nivolumab arm and $50 \%$ in the combination arm. Median OS and 2-year OS were 11.9 and $25.4 \%$ with nivolumab and 15.9 months and $31.7 \%$ with ipilimumab plus nivolumab. The most frequent grade 3-4 TRAEs described were asthenia, increase in aspartate or alanine aminotransferase, and lipase increase. Grade 3-4 TRAEs were more frequently reported in the combination arm (26 vs. $14 \%)$ than in the nivolumab arm $(26$ vs. $14 \%)(17,18)$.

Notable clinical activity with the same combination of ICIs was also described in the single-centre, single-arm, INITIATE study. In this trial, enrolling 38 MPM patients progressed after at least one line of platinum-based chemotherapy, only 34 were evaluable for response assessment.

The 12-week DCR, the primary endpoint of the study, was $33 \%$. Ten patients (29\%) experienced partial response and 13 (38\%) stable disease. The combination of ipilimumab plus nivolumab demonstrated a manageable safety profile. The most common any-grade TRAEs described were infusion-related reaction, dermatological toxicity, fatigue, anorexia, and diarrhea (19).

Pembrolizumab. KEYNOTE-158 is a single-arm, phase II study of pembrolizumab (200 mg every 3 weeks for a maximum of 35 cycles) in several pretreated malignancies. The primary endpoint was ORR. In this trial, 118 patients with previously treated MPM were enrolled. Ten patients $(8 \%)$ achieved an objective response at the sub-group analysis based on PD-L1 expression, ORR was $8 \%$ in PD-L1 positive MPM patients (PD-L1 expression $\geq 1$ ) and $13 \%$ in PD-L1 negative patients (PD-L1 expression $<1$ ). Notably, the median duration of objective response exceeded one year (14.3 months) (20). 
Popat et al (21) investigated the administration of pembrolizumab in the randomized, phase III PROMISE-meso trial. A total of 144 MPM patients progressed after first-line platinumbased chemotherapy were randomized (1:1) to receive pembrolizumab or chemotherapy according to investigators' choice (vinorelbine or gemcitabine). Patients randomized to chemotherapy who progressed were allowed to switch to investigational treatment. The study did not meet the primary endpoint of improvement in PFS by blinded independent central review (BICR). Indeed, the improvement in BICR-PFS observed in the immunotherapy arm compared to the chemotherapy arm (2.5 vs. 3.4 months, respectively; $\mathrm{P}=0.76)$, was not statistically significant. Similarly, no significant difference was observed in terms of OS (10.7 vs. 12.4 months, $\mathrm{P}=0.59)$. However, a significant ORR improvement for pembrolizumab compared to chemotherapy has been achieved (22 vs. 6\%, respectively, $\mathrm{P}=0.004)$.

Tremelimumab. In the phase II MESOT-TREM 2008 trial, 29 patients affected by previously treated pleural or peritoneal malignant mesothelioma received tremelimumab at the dose of $15 \mathrm{mg} / \mathrm{kg}$ every 90 days until disease progression or unacceptable toxicity. The primary endpoint was ORR with a target response rate of $17 \%$. Unfortunately, no patients experienced a completed response and only two patients achieved a partial response (ORR: 6.9\%). However, the median OS observed was 10.7 months (22). Subsequently, 29 patients were enrolled in the phase II MESOT-TREM 2012 trial investigating the anti CTLA-4 monoclonal antibody with an intensified schedule $(10 \mathrm{mg} / \mathrm{kg}$ every 4 weeks for 6 cycles and then every 12 weeks until disease progression or unacceptable toxicity). The primary endpoint of the study was the proportion of patients who achieved an immune-related objective response according to the immune-related modified RECIST. According to the statistical analyses, tremelimumab would have been considered active if at least four immune-related objective responses had been detected. Four patients (13.8\%) experience an immune-related partial response. Notably, only one patient had a partial response according to modified RECIST. Indeed, assessments by modified RECIST do not include the delayed responses, frequently observed with immunotherapy, occurring after initial progression of disease. The safety profile of the intensified schedule demonstrated a favorable safety profile: grade 3-4 toxicity were reported in two (7\%) patients (23). In the DETERMINE phase IIb trial, tremelimumab $(10 \mathrm{mg} / \mathrm{kg}$ every 4 weeks for 7 cycles and then every 12 weeks until disease progression or unacceptable toxicity) has been compared to placebo (2:1) in 568 patients affected by pleural or peritoneal mesothelioma progressed after one or two previous chemotherapy treatments. The study failed to meet its primary endpoint of OS in the intention-to-treat population. Indeed, the anti-CTLA-4 did not improve OS (7.7 vs. 7.3 months; HR, 0.92; $\mathrm{P}=0.41$ ) compared to placebo (24).

Durvalumab plus tremelimumab. The combination of durvalumab and tremelimumab have been evaluated in first or second-line in the non-randomized, phase II NIBIT-MESO-1 study enrolling 40 patients with pleural or peritoneal mesothelioma. Patients received initial induction therapy with tremelimumab $(1 \mathrm{mg} / \mathrm{kg})$ and durvalumab $(20 \mathrm{mg} / \mathrm{kg})$ every 4 weeks for 4 cycles followed by maintenance therapy with durvalumab $(20 \mathrm{mg} / \mathrm{kg})$ every 4 weeks for a maximum of 9 cycles. Patients who experienced disease progression during the maintenance phase or follow-up were allowed to restart the treatment. The primary endpoint of the study was the proportion of patients who achieved an immune-related objective response. The combination regimen demonstrated a meaningful activity with an immune-related objective response rate of $28 \%$ and a favorable safety profile (25). Recently, Calabrò et al (26) published 4-year survival and outcome data of patients enrolled in the NIBIT-MESO-1 study. Notably, the percentages of patients alive at 36 and 48 months were 20 and $15 \%$, respectively and the median OS was 16.5 months. A disease stabilization has been reported in $41 \%$ of patients who received immunotherapy retreatment, especially in those who previously experienced an objective response. Tumor mutation burden (TMB) is being evaluated as a predictive biomarker of ICI treatment outcome in a post hoc analysis of 28 patients with available tissue for testing. High-level TMB resulted associated with longer median OS compared to low-level TMB, although the difference was not statistically significant $(\mathrm{P}=0.06)$. Notably, only in the subset of patients retreated with the combination regimen the difference reached statistical difference $(\mathrm{P}=0.02)$.

Instead, Venkatraman et al (27) reported disappointing results in a phase II study investigating durvalumab (1,500 mg) and tremelimumab ( $75 \mathrm{mg}$ ) every 4 weeks for 4 cycles followed by durvalumab maintenance in 19 MPM patients progressed after first-line chemotherapy with platinum and pemetrexed. The study failed to meet its primary endpoint of ORR. The best objective response achieved was partial response observed in only one patient $(5 \%)$.

\section{Targeted agents in MPM}

The use of various targeted agents has been explored in MPM throughout the last years. To this regard, the most employed targets include neoangiogenesis, which is remarkably involved in tumor growth, and mesothelin, a glycosylphosphatidylinositol-linked cell surface molecule strongly expressed by mesothelial cells and mesothelioma cells, although this molecule is also expressed by other tumors and tissues. The following paragraphs describe the most relevant clinical studies targeting neoangiogenesis and mesothelin; noteworthy clinical outcomes are reported in Table III.

Inhibition of the vascular endothelial growth factor. Vascular endothelial growth factor (VEGF) is acknowledged as a relevant molecule for tumor development due to its pro-angiogenic action. Notably, MPM cells are known for releasing VEGF, hence developing an autocrine loop, which results in cancer progression and can be targeted for therapeutic purposes (28). Therefore, several clinical studies have focused on the inhibition of VEGF in MPM. In the open-label, randomized, phase III Mesothelioma Avastin Cisplatin Pemetrexed Study (MAPS), 448 patients with inoperable MPM were randomized $(1: 1)$ to receive chemotherapy with pemetrexed plus cisplatin alone or with the addition of bevacizumab at $15 \mathrm{mg} / \mathrm{kg} \mathrm{q} 21$ for up to six cycles. The primary end-point of the study, 
Table III. Relevant outcomes of studies involving immune targeted agents in MPM.

\section{A, VEGF INHIBITORS}

\begin{tabular}{|c|c|c|c|c|c|}
\hline Regimen & $\begin{array}{l}\text { First author, } \\
\text { year (trial) }\end{array}$ & Trial design & Patients/setting & Main efficacy outcomes & Refs. \\
\hline Bevacizumab & $\begin{array}{l}\text { Zalcman G, } \\
2016 \text { (MAPS) }\end{array}$ & $\begin{array}{l}\text { Randomized, phase III } \\
\text { trial }(1: 1) \text {-cisplatin } \\
\text { plus pemetrexed plus } \\
\text { bevacizumab vs. cisplatin } \\
\text { plus pemetrexed }\end{array}$ & $\begin{array}{l}448 \text { patients; } \\
\text { first-line }\end{array}$ & $\begin{array}{l}\text { Advantage in terms of OS with } \\
\text { chemotherapy plus bevacizumab } \\
\text { compared to chemotherapy } \\
\text { alone ( } 18.8 \text { vs. } 16.1 \text { months; } \\
\text { HR=0.77) }\end{array}$ & (29) \\
\hline \multirow[t]{2}{*}{ Nintedanib } & $\begin{array}{l}\text { Grosso F, } 2017 \\
\text { (LUME-Meso) }\end{array}$ & $\begin{array}{l}\text { Randomized, phase II } \\
\text { trial }(1: 1)^{\mathrm{a}} \text {-cisplatin } \\
\text { plus pemetrexed plus } \\
\text { nintedanib vs. cisplatin } \\
\text { plus pemetrexed plus } \\
\text { placebo }\end{array}$ & $\begin{array}{l}87 \text { patients; } \\
\text { first-line }\end{array}$ & $\begin{array}{l}\text { Advantage in terms of PFS with } \\
\text { chemotherapy plus nintedanib } \\
\text { compared to chemotherapy plus } \\
\text { placebo ( } 7.8 \text { vs. } 5.3 \text { months; } \\
\text { HR=0.54) }\end{array}$ & $(31)$ \\
\hline & $\begin{array}{l}\text { Scagliotti GV, } \\
2019 \\
\text { (LUME-Meso) }\end{array}$ & $\begin{array}{l}\text { Randomized, phase III } \\
\text { trial }(1: 1)^{\mathrm{a}} \text {-cisplatin } \\
\text { plus pemetrexed plus } \\
\text { nintedanib vs. cisplatin } \\
\text { plus pemetrexed plus } \\
\text { placebo }\end{array}$ & $\begin{array}{l}458 \text { patients; } \\
\text { first-line }\end{array}$ & $\begin{array}{l}\text { No advantage in terms of PFS } \\
\text { with chemotherapy plus } \\
\text { nintedanib compared to } \\
\text { chemotherapy plus placebo; } \\
(6.8 \text { months vs. } 7.0 \text { months } \\
\text { HR=1.01) }\end{array}$ & $(32)$ \\
\hline Cediranib & $\begin{array}{l}\text { Tsao AS, } 2019 \\
\text { (SWOG S0905) }\end{array}$ & $\begin{array}{l}\text { Randomized, phase II } \\
\text { trial (1:1)-platinum } \\
\text { plus pemetrexed plus } \\
\text { cediranib vs. platinum } \\
\text { plus pemetrexed plus } \\
\text { placebo }\end{array}$ & $\begin{array}{l}98 \text { patients; } \\
\text { first-line }\end{array}$ & $\begin{array}{l}\text { Numerical increase in terms of } \\
\text { PFS with chemotherapy plus } \\
\text { cediranib compared to } \\
\text { chemotherapy plus placebo } \\
\text { according to RECIST } \\
\text { ( } 7.2 \text { vs. } 5.6 \text { months; HR=0.71) } \\
\text { and modified RECIST } \\
\text { ( } 69 \text { vs. } 5.6 \text { months; HR=0.77) } \\
\text { No advantage in terms of OS } \\
\text { with chemotherapy plus } \\
\text { cediranib compared to } \\
\text { chemotherapy plus placebo } \\
(10.0 \text { vs. } 8.5 \text { months; HR: } 0.88 \text {; } \\
\text { P=0.28) }\end{array}$ & (33) \\
\hline Ramucirumab & $\begin{array}{l}\text { Pinto C, } 2021 \\
\text { (RAMES) }\end{array}$ & $\begin{array}{l}\text { Randomized, phase II } \\
\text { trial (1:1)-gemcitabine } \\
\text { plus ramucirumab vs. } \\
\text { gemcitabine plus placebo }\end{array}$ & $\begin{array}{l}161 \text { patients; } \\
\text { pre-treated }\end{array}$ & $\begin{array}{l}\text { Advantage in terms of OS with } \\
\text { chemotherapy plus ramucirumab } \\
\text { compared to chemotherapy plus } \\
\text { placebo ( } 13.8 \text { months vs. } \\
7.5 \text { months; HR=0.71) }\end{array}$ & (34) \\
\hline
\end{tabular}

$\mathrm{B}$, Mesothelin-targeting agents

\begin{tabular}{|c|c|c|c|c|c|}
\hline Regimen & $\begin{array}{c}\text { First author, } \\
\text { year (trial) }\end{array}$ & Trial design & Patients/setting & Main efficacy outcomes & Refs. \\
\hline Amatuximab & Hassan R, 2014 & $\begin{array}{l}\text { Single-arm, phase II } \\
\text { trial-amatuximab plus } \\
\text { cisplatin plus pemetrexed }\end{array}$ & $\begin{array}{l}89 \text { patients; } \\
\text { first-line }\end{array}$ & $\begin{array}{l}\text { 6-month PFS rate: } 51 \% \\
\text { Median OS: } 14.8 \text { months } \\
\text { DCR: } 90 \%\end{array}$ & $(35)$ \\
\hline SS1P & Hassan R, 2014 & $\begin{array}{l}\text { Phase I trial-cisplatin } \\
\text { plus pemetrexed plus } \\
\text { increasing doses of SS1P }\end{array}$ & $\begin{array}{l}24 \text { patients; } \\
\text { first-line }\end{array}$ & $\begin{array}{l}\text { MTD: } 45 \mathrm{mcg} / \mathrm{kg} \\
\text { ORR (global population): } 60 \% \\
\text { ORR (patients treated with } \\
\text { MTD): } 77 \%\end{array}$ & (36) \\
\hline
\end{tabular}


Table III. Continued.

B, Mesothelin-targeting agents

\begin{tabular}{|c|c|c|c|c|c|}
\hline Regimen & $\begin{array}{c}\text { First author, } \\
\text { year (trial) }\end{array}$ & Trial design & Patients/setting & Main efficacy outcomes & Refs. \\
\hline $\begin{array}{l}\text { Anetumab } \\
\text { ravtansine }\end{array}$ & $\begin{array}{l}\text { Kindler HL, } \\
2017\end{array}$ & $\begin{array}{l}\text { Randomized, phase II } \\
\text { trial }(2: 1) \text {-anetumab } \\
\text { ravtansine vs. vinorelbine }\end{array}$ & $\begin{array}{l}166 \text { patients; } \\
\text { pre-treated }\end{array}$ & $\begin{array}{l}\text { No advantage in terms of PFS } \\
\text { with anetumab ravtansine } \\
\text { compared to chemotherapy } \\
\text { ( } 4.3 \text { vs. } 4.5 \text { months; HR=1.215) } \\
\text { No advantage in terms of OS } \\
\text { with anetumab ravtansine } \\
\text { compared to chemotherapy } \\
(10.1 \text { vs. } 11.6 \text { months; } \\
\text { HR=0.721) }\end{array}$ & $(37)$ \\
\hline
\end{tabular}

DCR, disease control rate; HR, hazard ratio; MTD, maximum tolerated dose; OS, overall survival; PFS, progression-free survival; RECIST, response evaluation criteria in solid tumors; SS1P, SS1(dsFv)PE38. 'LUME-Meso was designed as a phase II/III trial; the different parts of the study are reported individually.

OS, was significantly improved in the experimental arm (18.8 vs. 16.1 months; HR=0.77), and the two arms had generally similar safety profiles, albeit significant differences were observed with regards to the incidence of grade 3 hypertension and thrombotic events, which were more frequent in the experimental arm, as expected from the safety profile of bevacizumab (29).

Nintedanib is a multi-target tyrosine kinase inhibitor (TKI) which exerts its anti-angiogenic activity by inhibiting VEGF receptors (VEGFR 1-3), although the agent is active also on multiple targets potentially involved in tumor progression, such as the fibroblast growth factor receptors (FGFR1-3), platelet-derived growth factor receptor (PDGFR $\alpha / \beta)$, and RET. Nintedanib is currently registered for the treatment of idiopathic pulmonary fibrosis due to its anti-fibrotic activity and for the management of previously treated non-small cell lung cancer (NSCLC) in combination with docetaxel (30). The effect of the addition of nintedanib to chemotherapy with cisplatin-pemetrexed was assessed in LUME-Meso trial, designed as a phase II/III trial. In the phase II part of the study, 87 patients with epithelioid or biphasic MPM were randomized (1:1) to receive cisplatin-pemetrexed plus either nintedanib or placebo; PFS, the primary end-point of this part of LUME-Meso, was significantly longer in the experimental arm (7.8 vs. 5.3 months; $\mathrm{HR}=0.54)$, with a trend towards OS improvement and more evident clinical benefit in the epithelioid histology, subsequently leading to the prosecution to phase III (31). In the second part of the study, which globally included 458 randomized patients, the PFS advantage for the nintedanib arm observed in phase II was not confirmed (6.8 vs. 7.0 months; $H R=1.01$ ), although the safety profile of the nintedanib arm was similar to the control arm with the exception of pulmonary embolism (6 vs. 3\%); hence, the combination of nintedanib plus chemotherapy was not registered in MPM (32).

Cediranib, an inhibitor active on VEGFR and PDGFR, was assessed in a randomized, placebo-controlled, phase II trial (SWOG S0905) designed to randomize treatment-naïve patients with unresectable MPM to receive cediranib or placebo in combination with platinum-pemetrexed for up to six cycles. The addition of cediranib resulted in numerically increased PFS according to RECIST (7.2 vs. 5.6 months; $\mathrm{HR}=0.71)$ and modified RECIST (6.9 vs. 5.6 months; $\mathrm{HR}=0.77$ ); however, no OS advantage was observed and patients in the experimental arm experienced more grade 3-4 adverse events (diarrhea, dehydration, hypertension, and weight loss), thus preventing further developments of the agent for this setting (33).

Ramucirumab is a monoclonal antibody directed against a specific VEGF receptor (VEGFR2). This agent was evaluated in the RAMES study, a multicenter, placebo-controlled trial in which 161 patients were randomized (1:1) to receive either ramucirumab or placebo in combination with gemcitabine as second-line treatment for inoperable MPM. In RAMES, the addition of ramucirumab to gemcitabine resulted improved OS over gemcitabine alone (13.8 vs. 7.5 months; HR=0.71), with a generally favorable safety profile; treatment-related grade 3-4 adverse events were reported in five $(6 \%)$ in the experimental arm and in four (5\%) patients in the control arm (34).

Targeted agents against mesothelin. Amatuximab is a chimeric monoclonal antibody directed against mesothelin, a membrane glycoprotein poorly present in normal adult tissues but highly expressed in multiple epithelial cancers, and especially MPM. In a single-arm, phase II trial, 89 patients received amatuximab on days 1 and 8 in combination with cisplatin and pemetrexed for up to six cycles, followed by maintenance with amatuximab. 6-month PFS-rate was $51 \%$, while median PFS and OS were 6.1 and 14.8 months, respectively. While the study did not meet the pre-specified end-point of improving median PFS to 8.7 months (corresponding to 6-month PFS rate of $62 \%$ ) over historical controls, the authors considered the achieved median OS encouraging and the safety profile of amatuximab acceptable (35). 
$\mathrm{SS} 1(\mathrm{dsFv}) \mathrm{PE} 38$ (SS1P) is another drug targeting mesothelin, and more specifically a recombinant anti-mesothelin immunotoxin. In a phase I trial, 24 patients affected by untreated, inoperable epithelial or biphasic MPM, received cisplatin-pemetrexed for up to 6 cycles with increasing doses of SS1P. The drug was generally well tolerated at $45 \mathrm{mcg} / \mathrm{kg}$ (which resulted the maximum tolerated dose; MTD). Within the global trial population, ORR was $60 \%$, while the patients treated with $45 \mathrm{mcg} / \mathrm{kg}$ achieved an ORR of $77 \%$. Notably, the response was associated with reduction of serum mesothelin, megakaryocyte potentiating factor, and cancer antigen 125 levels (36).

Anetumab ravtansine is composed by a mesothelin monoclonal antibody conjugated to the maytansinoid microtubule inhibitor DM4, which is bound and internalized by mesothelin-expressing tumor cells. After showing a favorable safety profile, the activity and safety of anetumab ravtansine were assessed in a randomized phase II trial in which previously treated patients with unresectable MPM over-expressing mesothelin were randomized (2:1) to receive anetumab ravtansine or vinorelbine. Anetumab ravtansine was not superior to vinorelbine in terms of median PFS, the primary end-point (4.3 vs. 4.5 months; HR=1.215), or OS (10.1 vs. 11.6 months; $\mathrm{HR}=0.721$ ), although the experimental agent was well tolerated (37).

Innovative approaches: Chimeric Antigen Receptor T cell therapy. Chimeric Antigen Receptor (CAR) T cell therapy is a novel strategy for treating solid tumors and hematological malignancies. This approach combines features of cancer immunotherapy, as well as targeted therapy; indeed, CAR T cells involve the genetic modification of autologous or donor $\mathrm{T}$ cells to express a tumor-associated antigen-specific chimeric antigen receptor on their cell surface. To date, CAR T therapy has been approved for the treatment of relapsed hematological malignancies such as B cell lymphoblastic leukemia and non-Hodgkin lymphoma, with outstanding outcomes; furthermore, several clinical trials are currently exploring the potential role of CAR T in solid tumors. In spite of its effectiveness, the broad use of CAR $T$ has been limited so far by its cost and severe, potentially life-threatening toxicities, which require the maintenance of non-negligible resources, both in terms of financial availability and in terms of facilities and clinical expertise (38). CAR-T therapy using mesothelin as a target has been investigated in several phase I clinical trials involving, among others, MPM. In a phase I trial led by the National Cancer Institute (NCT01583686) involving the use of anti-mesothelin CAR T ( $\mathrm{SS} 1 \mathrm{scFv}$ ) in solid tumors expressing mesothelin showed an acceptable safety profile but modest anti-tumor efficacy, and was terminated due to extremely low patient accrual $(39,40)$. In another phase I trial (NCT01355965), 18 patients with MPM or pancreatic ductal adenocarcinoma were treated with anti-mesothelin CAR T (SS1 mouse scFv fused to 4-1-BB and TCR- $\zeta$ domains), with transient tumor response and acceptable safety, although one MPM patient experienced severe anaphylaxis after repeated infusions (41). Finally, in another phase I trial (NCT02159716), 15 patients with MPM, pancreatic ductal adenocarcinoma or ovarian cancer received anti mesothelin CAR T (SS1 mouse $\mathrm{scFv}$ fused to $4-1-\mathrm{BB}$ and $\mathrm{TCR}-\zeta$ domains) alone or with cyclophosphamide as lymphodepleting agent; disease stabilization was observed in 11 out of 15 patients at the first assessment at 28 days and in 3 out of 8 patients on follow-up at months 2-3 (42). Furthermore, the synergy between immune checkpoint inhibitors and CAR-T therapy might result in decreased $\mathrm{T}$ cell exhaustion, hence resulting in improved efficacy (43). The combination of regional mesothelin-targeted CAR-T cell therapy and pembrolizumab was recently investigated in a population of 18 MPM patients. Eight patients achieved stable disease for $\geq 6$ months, and two exhibited complete metabolic response at PET scan; the median OS was 23.9 months, and 1-year OS was $83 \%$ (44).

\section{Conclusion}

Malignant pleural mesothelioma has been considered an orphan disease for decades, and few innovative, effective treatments have been implemented in clinical practice until recently. The currently available evidence-based treatment approaches in unresectable MPM are reported in the Table SI $(45,46)$. While some interest has raised in the use of anti-angiogenic agents, the global efficacy results have generally been underwhelming, so far. Furthermore, in contrast to what is being observed in several other solid tumors, a promising actionable oncogenic driver with potential therapeutic impact has to be identified yet. Despite promising results in phase II trials, targeted agents often failed in phase III trials, probably for the incapacity to properly identify those patients who might benefit from targeted treatments. Hence, novel studies designed to address the lack of predictive biomarkers for targeted agents in MPM are highly warranted, as well as translational studies designed to detect novel potential therapeutic targets. In this context, the advent of immunotherapy with ICIs has generated fresh optimism due to the promising results observed in MPM patients.

However, mesothelioma, unlike other malignancies, is not considered a highly immunogenic cancer. This poor immunogenicity could explain the relatively modest response rates with checkpoint inhibitors compared to other cancers. Mesothelioma indeed is considered to have a low tumor mutational burden (TMB). Considering that PD-L1 expression failed to predict survival benefit with checkpoint inhibitors in phase III clinical trials in MPM, the precise mechanisms determining response to immunotherapy in this cancer are still unknown (47).

More specifically, data from the CheckMate 743 trial, supporting the use of the combination of ipilimumab and nivolumab for previously untreated unresectable MPM patients, have changed the first-line standard-of-care treatment of this malignancy and have showed the benefit of immunotherapy even in the sarcomatoid histology, which is usually associated with poor outcomes.

Although the trial was not powered to detect differences between epithelioid and non-epithelioid subgroups, patients with epithelioid mesothelioma appear to have little benefit from immunotherapy. The survival benefit observed with the dual immunotherapy regimen in patients with sarcomatoid mesothelioma could be mainly explained by the low responsivity to chemotherapy observed in this MPM subtype (48). 
Notably, these results are consistent with the outcomes observed in a retrospective study investigating the administration of checkpoint inhibitors in 20 MPM patients demonstrated that patients with sarcomatoid MPM had longer median PFS and OS (>28 months) compared to patients with epithelioid subtype ( 3 and 11 months, respectively), suggesting noteworthy effectiveness of dual immune checkpoint blockade for the treatment of sarcomatoid MPM. Furthermore, the authors observed that high proportions of $\mathrm{CD}^{+} \mathrm{T}$ cells and $\mathrm{CD} 45 \mathrm{RO}^{+}$ memory cells were associated with prolonged median PFS and OS in sarcomatoid patients (49).

Moreover, results from CheckMate 743 suggested a survival benefit with chemotherapy in patients with PD-L1 expression $<1 \%$, however, this explorative and descriptive finding should be interpreted with caution.

While the most relevant achievements in the management of MPM involve dual checkpoint blockade, the results of CONFIRM trial suggested that also single-agent nivolumab is a valid option treatment for patients with MPM who had previously received first-line chemotherapy, especially when additional therapeutic options are lacking. Notably, while the PROMISE-meso trial did not show superiority of pembrolizumab over single-agent chemotherapy in terms of PFS or OS, immunotherapy achieved higher ORR than chemotherapy, which should be considered non-negligible, especially when taking into account that the trial included previously treated patients.

The demonstration of efficacy achieved by cancer immunotherapy represent a real cornerstone for the management of MPM and opens future research to additional steps. Currently, several clinical trials are exploring various combinations as well as the use of novel compounds, eventually associated with immunotherapy. In the randomized phase III BEAT-MESO trial, for instance, first-line chemotherapy plus bevacizumab and atezolizumab is being compared to chemotherapy plus bevacizumab alone in unresectable MPM patients (50).

In addition to defining the efficacy of immune checkpoint blockade plus angiogenesis inhibition, the results of this study might also be helpful to better elucidate the role of bevacizumab in the treatment of MPM since, following the results of MAPS trial, the National Comprehensive Cancer Network (NCCN) guidelines have included the combination of pemetrexed plus cisplatin and bevacizumab as an option for first-line therapy although it has not yet been approved by FDA. In spite of these encouraging results, other questions need to be addressed. In first place, there is still lack of suitable predictive biomarkers which might improve patient selection. In second place, some settings and clinical approaches need to be re-elaborated with the use of specific, 'ad hoc' studies, with particular reference to localized, potentially operable MPM; indeed, since the use of trimodal treatment with chemotherapy remains controversial, and since immunotherapy is showing a non-negligible activity in the neoadjuvant setting for other tumors, such as non-small cell lung cancer, the development of studies involving immunotherapy in potentially operable MPM are warranted.

\section{Acknowledgements}

Not applicable.

\section{Funding}

No funding was received.

\section{Availability of data and materials}

The datasets used and/or analyzed in the current study are available from the corresponding author on reasonable request.

\section{Authors' contributions}

ER, CG, FB, GB and CD designed the review. ER and CG wrote the manuscript. FB, GB and $\mathrm{CD}$ were involved in the collection and collation of references, in evaluating and reviewing the manuscript. All authors read and approved the final manuscript. Data authentication is not applicable.

\section{Ethics approval and consent to participate}

Not applicable.

\section{Patient consent for publication}

Not applicable.

\section{Competing interests}

ER: Personal fees from Bristol Myers Squibb, Boehringer Ingelheim; FB: no disclosures; GB: no disclosures; CD: Astra Zeneca, Merck Sharp Dohme, Roche; CG: Personal fees from Bristol Myers Squibb, Boehringer Ingelheim, AstraZeneca, Merck Sharp Dohme, Roche, Takeda; Advisory Board: Merck Sharp Dohme.

\section{References}

1. Davis AP, Kao SC, Clarke SJ, Boyer M and Pavlakis N: Emerging biological therapies for the treatment of malignant pleural mesothelioma. Expert Opin Emerg Drugs 26: 179-192, 2021.

2. Parker $C$ and Neville E: Lung cancer ${ }^{*} 8$ : Management of malignant mesothelioma. Thorax 58: 809-813, 2003.

3. Husain AN, Colby TV, Ordóñez NG, Allen TC, Attanoos RL, Beasley MB, Butnor KJ, Chirieac LR, Churg AM, Dacic S, et al: Guidelines for pathologic diagnosis of malignant mesothelioma 2017 update of the consensus statement from the International mesothelioma interest group. Arch Pathol Lab Med 142: 89-108, 2018.

4. Baas P, Scherpereel A, Nowak AK, Fujimoto N,Peters S, Tsao AS, Mansfield AS, Popat S, Jahan T, Antonia S, et al: First-line nivolumab plus ipilimumab in unresectable malignant pleural mesothelioma (CheckMate 743): A multicentre, randomised, open-label, phase 3 trial. Lancet 397: 375-386, 2021.

5. Scherpereel A, Antonia S, Bautista Y, Grossi F, Kowalski D, Zalcman G, Nowak A, Fujimoto N, Peters S, Tsao A, et al: First-line nivolumab (NIVO) plus ipilimumab (IPI) versus chemotherapy (chemo) for the treatment of unresectable malignant pleural mesothelioma (MPM): Patient-reported outcomes (PROs) from CheckMate 743. Ann Oncol 31 (Suppl 7): S1441, 2020.

6. Wright K: FDA approves nivolumab plus ipilimumab for previously untreated unresectable malignant pleural mesothelioma. Oncology (Williston Park) 34: 502-503, 2020.

7. Peters S, Scherpereel A, Cornelissen R, Oulkhouir Y, Greillier L, Kaplan MA, Talbot T, Monnet I, Hiret S, Baas P, et al: First-line nivolumab (NIVO) plus ipilimumab (IPI) vs chemotherapy (chemo) in patients (pts) with unresectable malignant pleural mesothelioma (MPM): 3-year update from CheckMate 743. Ann Oncol 32 (Suppl 5): S1283-S1346, 2021. 
8. Forde PM, Sun Z, Anagnostou V, Kindler HL, Purcell WT, Goulart BHL, Dudek AZ, Borghaei H, Brahmer JR and Ramalingam SS: PrE0505: Phase II multicenter study of anti-PD-L1, durvalumab, in combination with cisplatin and pemetrexed for the first-line treatment of unresectable malignant pleural mesothelioma (MPM)-A PrECOG LLC study. J Clin Oncol 38 (Suppl 15): S9003, 2020.

9. Nowak AK, Lesterhuis WJ, Kok PS, Brown C, Hughes BG, Karikios DJ, John T, Kao SC, Leslie C, Cook AM, et al: Durvalumab with first-line chemotherapy in previously untreated malignant pleural mesothelioma (DREAM): A multicentre, single-arm, phase 2 trial with a safety run-in. Lancet Oncol 21: 1213-1223, 2020

10. Forde PM, Nowak AK, Kok PS, Brown C, Sun Z, Anagnostou V, O'Byrne KJ, Yip S, Cook A, Lesterhuis WJ, et al: DREAM3R: Durvalumab with chemotherapy as first-line treatment in advanced pleural mesothelioma-a phase 3 randomized trial. J Chin Oncol 39: TPS8586, 2021.

11. Quispel-Janssen J, van der Noort V, de Vries JF, Zimmerman M, Lalezari F, Thunnissen E, Monkhorst K, Schouten R, Schunselaar L, Disselhorst M, et al: Programmed Death 1 Blockade with nivolumab in patients with recurrent malignant pleural mesothelioma. J Thorac Oncol 13: 1569-1576, 2018.

12. Okada M, Kijima T, Aoe K, Kato T, Fujimoto N, Nakagawa K, Takeda Y, Hida T, Kanai K, Imamura F, et al: Clinical efficacy and safety of nivolumab: Results of a multicenter, open-label, single-arm, Japanese phase II study in malignant pleural mesothelioma (MERIT). Clin Cancer Res 18: 5485-5492, 2019.

13. Hayashi H, Okada M, Kijima T, Aoe K, Kato T, Fujimoto N, Nakagawa K, Takeda Y, Hida T, Kanai K, et al: Three-year follow-up results of the MERIT trial: A Japanese phase II study of nivolumab in malignant pleural mesothelioma. Ann Oncol 31: S1076, 2020.

14. Fennell DA, Kirkpatrick E, Cozens K, Nye M, Lester J, Hanna G, Steele N, Szlosarek P, Danson S, Lord J, et al: CONFIRM A double-blind, placebo-controlled phase III clinical trial investigating the effect of nivolumab in patients with relapsed mesothelioma: Study protocol for a randomised controlled trial. Trials 19: 233, 2018

15. Fennell D, Ottensmeier C, Califano R, Hanna G, Ewings S, Hill K, Wilding S, Danson S, Nye M, Steele N, et al: Nivolumab versus placebo in relapsed malignant mesothelioma: The CONFIRM phase 3 trial. J Thorac Oncol 16 (Suppl): S62, 2020.

16. Fennell DA, Ewings S, Ottensmeier C, Califano R, Hanna GG, Hill K, Danson S, Steele N, Nye M, Johnson L, et al: Nivolumab versus placebo in patients with relapsed malignant mesothelioma (CONFIRM): A multicentre, double-blind, randomised, phase 3 trial. Lancet Oncol 22: 1530-1540, 2021.

17. Scherpereel A, Mazieres J, Greillier L, Lantuejoul S Dô P, Bylicki O, Monnet I, Corre R, Audigier-Valette C, Locatelli-Sanchez M, et al: Nivolumab or nivolumab plus ipilimumab in patients with relapsed malignant pleural mesothelioma (IFCT-1501 MAPS2): A multicentre, open-label, randomised, non-comparative, phase 2 trial. Lancet Oncol 20: 239-253, 2019.

18. Zalcman G, Mazieres J, Greillier L, Brosseau S, Lantuejoul S, DO P, Bylicki O, Monnet I, Corre R, Audigier-Valette C, et al: 2nd/3rd-line nivolumab vs nivo plus ipilimumab in malignant pleural mesothelioma: long-term results of IFCT-1501 MAPS2 phase 2R trial with a focus on hyperprogression (HPD). Ann Oncol 30 (Suppl 5): v747-v755, 2019.

19. Disselhorst MJ, Quispel-Janssen J, Lalezari F, Monkhost K, de Vries JF, van der Noort V, Hams E, Burgers S and Baas P: Ipilimumab and nivolumab in the treatment of recurrent malignant pleural mesothelioma (INITIATE): Results of a prospective, single-arm, phase 2 trial. Lancet Respir Med 7: 260-270, 2019.

20. Yap TA, Nakagawa K, Fujimoto N, Kuribayashi K, Guren TK Calabro L, Shapira-Frommer R, Gao B, Kao S, Matos I, et al: Efficacy and safety of pembrolizumab in patients with advanced mesothelioma in the open-label, single-arm, phase 2 KEYNOTE-158 study. Lancet Respir Med 9: 613-621, 2021.

21. Popat S, Curioni-Fontecedro A, Dafni U, Shah R, O'Brien M, Pope A, Fisher P, Spicer J, Roy A, Gilligan D, et al: A multicentre randomised phase III trial comparing pembrolizumab versus single-agent chemotherapy for advanced pre-treated malignant pleural mesothelioma: The European thoracic oncology platform (ETOP 9-15) PROMISE-meso trial. Ann Oncol 31: 1734-1745, 2020.
22. Calabrò L, Morra A, Fonsatti E, Cutaia O, Amato G, Giannarelli D, Di Giacomo AM, Danielli R, Altomonte M, Mutti L and Maio M: Tremelimumab for patients with chemotherapy-resistant advanced malignant mesothelioma: An open-label, single-arm, phase 2 trial. Lancet Oncol 14: 1104-1111, 2013.

23. Calabrò L, Morra A, Fonsatti E, Cutaia O, Fazio C, Annesi D, Lenoci M, Amato G, Danielli R, Altomonte M, et al: Efficacy and safety of an intensified schedule of tremelimumab for chemotherapy-resistant malignant mesothelioma: An open-label, single-arm, phase 2 study. Lancet Resp Med 3: 301-309, 2015.

24. Maio M, Scherpereel A, Calabrò L, Aerts J, Perez SC, Bearz A, Nackaerts K, Fennell DA, Kowalski D, Tsao AS, et al: Tremelimumab as second-line or third-line treatment in relapsed malignant mesothelioma (DETERMINE): A multicentre, international, randomised, double-blind, placebo-controlled phase $2 \mathrm{~b}$ trial. Lancet Oncol 18: 1261-1273, 2017.

25. Calabrò L, Morra A, Giannarelli D, Amato G, D'Incecco A, Covre A, Lewis A, Rebelatto MC, Danielli R, Altomonte M, et al: Tremelimumab combined with durvalumab in patients with mesothelioma (NIBIT-MESO-1): An open-label, non-randomised, phase 2 study. Lancet Respir Med 6: 451-460, 2018.

26. Calabrò L, Rossi G, Morra $\mathrm{A}$, Rosati $\mathrm{C}$, Cutaia $\mathrm{O}$, Daffinà MG, Altomonte M, Di Giacomo AM, Casula M, Fazio C, et al: Tremelimumab plus durvalumab retreatment and 4-year outcomes in patients with mesothelioma: A follow-up of the open-label, non randomised, phase 2 NIBIT-MESO-1 study. Lancet Respir Med 9: 969-976, 2021.

27. Venkatraman D, Anderson A, Digumarthy S, Lizotte PH and Awad MM: Phase 2 study of tremelimumab plus durvalumab for previously-treated malignant pleural mesothelioma (MPM). J Chin Oncol 37 (Suppl 15): 8549-8549, 2019.

28. Masood R, Kundra A, Zhu S, Xia G, Scalia P, Smith DL and Gill PS: Malignant mesothelioma growth inhibition by agents that target the VEGF and VEGF-C autocrine loops. Int J Cancer 104: 603-610, 2003.

29. Zalcman G, Mazieres J, Margery J, Greillier L, Audigier-Valette C, Moro-Sibilot D, Molinier O, Corre R, Monnet I, Gounant V, et al: Bevacizumab for newly diagnosed pleural mesothelioma in the Mesothelioma Avastin Cisplatin Pemetrexed Study (MAPS): A randomised, controlled, open-label, phase 3 trial. Lancet 387: 1405-1414, 2016

30. Roth GJ,Binder R, Colbatzky F, Dallinger C, Schlenker-Herceg R, Hilberg F, Wollin SL and Kaiser R: Nintedanib: From discovery to the clinic. J Med Chem 58: 1053-1063, 2015.

31. Grosso F, Steele N, Novello S, Nowak AK, Popat S, Greillier L, John T, Leighl NB, Reck M, Taylor P, et al: Nintedanib plus pemetrexed/cisplatin in patients with malignant pleural mesothelioma: Phase II results from the randomized, placebo-controlled LUME-Meso Trial. J Clin Oncol 35: 3591-3600, 2017.

32. Scagliotti GV, Gaafar R, Nowak AK, Nakano T, van Meerbeeck J, Popat S, Vogelzang NJ, Grosso F, Aboelhassan R, Jakopovic M, et al: Nintedanib in combination with pemetrexed and cisplatin for chemotherapy-naive patients with advanced malignant pleural mesothelioma (LUME-Meso): A double-blind, randomised, placebo-controlled phase 3 trial. Lancet Respir Med 7: 569-580, 2019.

33. Tsao AS, Miao J, Wistuba II, Vogelzang NJ, Heymach JV, Fossella FV, Lu C, Velasco MR, Box-Noriega B, Hueftle JG, et al: Phase II trial of cediranib in combination with cisplatin and pemetrexed in chemotherapy-naïve patients with unresectable malignant pleural mesothelioma (SWOG S0905). J Clin Oncol 37: 2537-2547, 2019.

34. Pinto C,Zucali PA,Pagano M, Grosso F, Pasello G, Garassino MC, Tiseo M, Soto Parra H, Grossi F, Cappuzzo F, et al: Gemcitabine with or without ramucirumab as second-line treatment for malignant pleural mesothelioma (RAMES): A randomised, double-blind, placebo-controlled, phase 2 trial. Lancet Oncol 22: $1438-1447,2021$.

35. Hassan R, Kindler HL, Jahan T, Bazhenova L, Reck M, Thomas A, Pastan I, Parno J, O'Shannessy DJ, Fatato P, et al: Phase II clinical trial of amatuximab, a chimeric antimesothelin antibody with pemetrexed and cisplatin in advanced unresectable pleural mesothelioma. Clin Cancer Res 20: 5927-5936, 2014.

36. Hassan R, Sharon E, Thomas A, Zhang J, Ling A, Miettinen M, Kreitman RJ, Steinberg SM, Hollevoet K and Pastan I: Phase 1 study of the antimesothelin immunotoxin SS1P in combination with pemetrexed and cisplatin for front-line therapy of pleural mesothelioma and correlation of tumor response with serum mesothelin, megakaryocyte potentiating factor, and cancer antigen 125. Cancer 120: 3311-3319, 2014 
37. Kindler HL, Novello S, Fennell DA, Blumenschein G, Bearz A Ceresoli G, Aerts J, Spicer J, Taylor P, Taylor P, et al: Randomized phase II study of anetumab ravtansine or vinorelbine in patients with malignant pleural mesothelioma. J Thorac Oncol 12: S1746, 2017.

38. Sterner RC and Sterner RM: CAR-T cell therapy: Current limitations and potential strategies. Blood Cancer J 11: 69, 2021.

39. Castelletti L, Yeo D, van Zandwijk N and Rasko JEJ: Anti-Mesothelin CAR T cell therapy for malignant mesothelioma. Biomark Res 9: 11, 2021.

40. NCT01583686: CAR T cell receptor immunotherapy targeting mesothelin for patients with metastatic cancer. https://clinicaltrials.gov/ct2/show/NCT01583686.

41. Maus MV, Haas AR, Beatty GL, Albelda SM, Levine BL, Liu X, Zhao Y, Kalos $\mathrm{M}$ and June $\mathrm{CH}$ : T cells expressing chimeric antigen receptors can cause anaphylaxis in humans. Cancer Immunol Res 1: 26-31, 2013.

42. Haas AR, Tanyi JL, O'Hara MH, Gladney WL, Lacey SF, Torigian DA, Soulen MC, Tian L, McGarvey M, Nelson AM, et al: Phase I study of lentiviral-transduced chimeric antigen receptor-modified t cells recognizing mesothelin in advanced solid cancers. Mol Ther 27: 1919-1929, 2019.

43. Chintala NK, Restle D, Quach H, Saini J, Bellis R, Offin M, Beattie J and Adusumilli PS: CAR T-cell therapy for pleural mesothelioma: Rationale, preclinical development, and clinical trials. Lung Cancer 157: 48-59, 2021.

44. Adusumilli PS, Zauderer MG, Rivière I, Solomon SB, Rusch VW, O'Cearbhaill RE, Zhu A, Cheema W, Chintala NK, Halton E, et al: A Phase I trial of regional mesothelin-targeted CAR T-cell therapy in patients with malignant pleural disease, in combination with the anti-PD-1 agent pembrolizumab. Cancer Discov 11: 2748-2763, 2021.
45. Popat S, Baas P, Faivre-Finn C, Girard N, Nicholson AG, Nowak AK, Opitz I, Scherpereel A and Reck M; ESMO Guidelines Committee Electronic address: clinicalguidelines@ esmo.org: Malignant pleural mesothelioma: ESMO Clinical Practice Guidelines for diagnosis, treatment and follow-up. Ann Oncol 33: 129-142, 2022.

46. NCCN: Clinical Practice Guidelines in Oncology (NCCN Guidelines ${ }^{\circledR}$ ) Malignant Pleural Mesothelioma version 1.2022-December22, 2021. https://www.nccn.org/professionals/physician_gls/pdf/mpm.pdf.

47. Harber J, Kamata T, Pritchard C and Fennell D: Matter of TIME: The tumor-immune microenvironment of mesothelioma and implications for checkpoint blockade efficacy. J Immunother Cancer 9: e003032, 2021.

48. van Zandwijk N, Clarke C, Henderson D, Musk AW, Fong K, Nowak A, Loneragan R, McCaughan B, Boyer M, Feigen M, et al: Guidelines for the diagnosis and treatment of malignant pleural mesothelioma. J Thorac Dis 5: E254-E307, 2013.

49. Brockwell NK, Alamgeer M, Kumar B, Rivalland G, John T and Parker BS: Preliminary study highlights the potential of immune checkpoint inhibitors in sarcomatoid mesothelioma. Transl Lung Cancer Res 9: 639-645, 2020.

50. NCT03762018: BEAT-meso: bevacizumab and atezolizumab in malignant pleural mesothelioma. https://clinicaltrials. gov/ct2/show/NCT03762018. 